\title{
¿ES POSIBLE UNA RENOVACIÓN DE LA METAFISICA?
}

La cuestión que quisiéramos tratar, y que no resolveremos, es ésta: ¿es posible una renovación de la metafísica? Recordemos el pasaje en que nos dice Bergson que si le preguntasen por la posibilidad de una nueva forma de la novela, respondería: si supiese lo que va a ser esa forma de novela, la escribiría. Asimismo, si es posible una renovación de la metafísica, y si la veo posible, debo volverla real, no podrá saberse si era posible más que después de haberla vuelto real. De hecho, no responderemos, en absoluto, a la cuestión, pero será la ausencia de respuesta lo que constituirá la respuesta; y nos moveremos dentro de la metafísica, nos sumergiremos en el seno de la metafísica, simplemente examinando la cuestión de saber si es posible tal renovación.

La posición del filósofo es en el día de hoy la posición del filósofo en un estado de crisis, crisis general, simbolizada y en gran parte causada por una crisis del pensamiento científico. Como quizá nunca antes, se encuentra la ciencia en presencia de algunos de sus límites. Encima, muchos conceptos científicos, que por lo demás son al mismo tiempo conceptos del sentido común, o cuando menos de un sentido común elaborado, el espacio, el tiempo, la causalidad, la continuidad, están puestos en tela de juicio. Y si completamos la física con la psicología, podríamos decir que no es sólo el principio de indeterminación, sino también la idea freudiana de super-determinación, lo que nos hace rebasar la idea corriente de causalidad.

Mas no es la primera vez que se ha encontrado el hombre ante una crisis. Cabría incluso preguntarse - pero dejaremos de lado esta cuestión después de haberla suscitado- si el pensamiento no está siempre en estado de crisis, si la crisis no es el régimen normal del pensamiento. En todo caso, podemos ver que una crisis tan importante como la nuestra se produjo entre el fin del mundo antiguo y el principio del mundo moderno. Para los antiguos (con algunas excepciones, como Meliso y Anaximandro, que por lo demás, y justo por esta razón, son tratados con bastante dureza por Aristóteles), era el mundo finito, el tiempo una inferioridad, la materia incognoscible; por encima del alma ponían los platónicos las Ideas; el mal era ante todo ignorancia. Para los modernos, es el mundo infinito, el tiempo forma parte de su esencia, la materia es esencialmente cognoscible, el alma alzada bien a menudo, como ha dicho Bergson, por encima de las Ideas, el mal una realidad positiva. La última de estas oposiciones, quizá incluso la penúltima, se deben al advenimiento del cristianismo. Las tres primeras se explican ante todo por el desarrollo de la ciencia. Sin duda que entre estos dos grandes hechos hay a la vez oposi- 
ciones y coincidencias. Quizá la idea de que la materia ha sido creada por Dios no carezca de relación con la idea de que es enteramente cognoscible; y bajo este punto de vista, puede irse bastante fácilmente del cristianismo al cartesianismo. Pero lo que por el momento nos importa es ver en esta revolución del pensamiento humano algo análogo a aquella en cuya presencia y seno estamos.

Se han desvanecido muchos principios clásicos, han desaparecido los cuadros en que se encerraban las cosas; parecen haberse evaporado las cosas mismas que entraban en esos cuadros.

Partiendo de aquí podemos echar una ojeada a las grandes filosofías tales como nos las lega la tradición; y empezaríamos por encontrarnos en presencia, por un lado, del racionalismo clásico, por otro lado, del empirismo. El primero nos parece constituído bien a menudo por una unión de la lógica aristotélica y el entendimiento cartesiano. Se trataría, entonces, de ver el valor de una y otro. Sacando a relucir los juicios de relación, nos llevarían los logísticos a discutir la lógica aristotélica. Y en cuanto al entendimiento cartesiano, implica la afirmación de la preeminencia de lo perfecto, de lo infinito, sobre lo imperfecto y lo finito. Podríamos desenmascarar en él lo que con gusto llamaríamos la preeminencia de lo seudo-positivo sobre lo que es realmente positivo; pues lo que nos es dado en la experiencia es lo particular y lo que por una especie de retrospección llamamos lo imperfecto y lo finito. Pero si no aceptamos el racionalismo clásico, no será ello una razón para aceptar el empirismo, al menos bajo su forma tradicional; $y$, en efecto, bajo esta forma tradicional, nos presenta el mundo constituído por términos separados unos de otros, dislocados; tal es el empirismo de Locke; y sin duda no podría decirse del todo la misma cosa del de Hume, que por el lugar que da al hábito, y hasta por su concepción de las transiciones entre los pensamientos, rebasa el empirismo tal cual se lo describe corrientemente. Sin que por ello sea menos verdad que en Hume mismo hay una muy fuerte tendencia a subrayar el carácter discontinuo de la vida consciente.

Es el hecho de no ver el empirismo en la realidad las relaciones ni conservar más que los términos, lo que explica que haya afirmado el racionalismo que las relaciones le son impuestas a la experiencia por el espíritu. Es la debilidad del empirismo lo que constituye la fuerza del racionalismo. E inversamente, es la afirmación de lo perfecto y lo infinito, lo que nos parece una de las debilidades del racionalismo que constituyen la fuerza del empirismo. Observemos, por lo demás, que hay similitudes bastante profundas entre las dos doctrinas, ante todo por el hecho mismo de no ver ni una ni otra las relaciones en el seno de la experiencia; en segundo lugar, por el hecho de moverse una y otra en lo que llama Whitehead el dominio de la inmediación presentacional; y este segundo rasgo está ligado a la preeminencia, todo a lo largo de la historia de la filosofía, del sentido de la vista, en detrimento de los demás datos 
sensibles o afectivos; punto sobre el cual podríamos apelar al testimonio de Maine de Biran, de Bergson, de Scheler, de Heidegger.

Si no nos damos por contentos ni con el empirismo clásico, ni con el racionalismo clásico, pueden retener nuestra atención dos grandes formas de doctrinas, las doctrinas fundadas sobre el ser y las doctrinas fundadas sobre la totalidad. Como ha dicho Kierkegaard, podemos criticar primero el punto de partida del hegelianismo, la crítica del aquí y el ahora, luego el fin del hegelianismo, es decir, la idea de Absoluto, y por último el medio del hegelianismo, es decir, su concepción de la mediación. La crítica del aquí y el ahora se funda en una cierta concepción del lenguaje por la que sería éste la expresión completa de la realidad. Pero si se dice que el lenguaje está hecho ante todo para designar, ya no hay nada que puede asombrarnos en el hecho de que la palabra con que designe cada uno de nosotros su aquí y su ahora sea la misma para todos. En cuanto a la idea de que se alcance lo Absoluto con la evolución de las teorías filosóficas tomadas en conjunto, la pone en tela de juicio el hecho mismo de no haber, al menos hasta aquí, un final de las doctrinas filosóficas y de haber vuelto, después del propio Hegel, el momento de la subjetividad, que él pensaba haber criticado definitivamente. Por último, ¿debe la mediación presentarse siempre como una actividad de contradicción? Es un punto aún que merecería discutirse. En cuanto a las filosofías fundadas sobre el ser, se presentan bien a menudo como implicando respuestas acerca del ser; pero Heidegger admitiría que el ser es objeto de interrogatorio y no de respuesta. Se trataría, entonces, de buscar la razón misma de este interrogatorio; y una de las respuestas posibles es la de que la idea de ser es una idea abstracta, es en el fondo una categoría gramatical a la que nada responde naturalmente en la naturaleza de las cosas.

Otros filósofos se apoyarán sobre experiencias, sea la experiencia de la angustia con Kierkegaard, la experiencia de la duración con Bergson. Pero no estamos, en absoluto, seguros de que nos abra la realidad metafísica una u otra de estas experiencias; y la continuidad que caracteriza la experiencia bergsoniana quizá no sea más primitiva que la discontinuidad.

Entonces parecería legítimo volverse hacia la ciencia, dado que es de una observación hecha acerca de la crisis científica de donde partimos para sentar que hay realmente una crisis del pensamiento moderno. Pero no es posible aislar completamente la ciencia de su punto de partida, suministrado por las sensaciones recibidas de nosotros. $\mathrm{Y}$ son estas sensaciones recibidas de nosotros lo que verdaderamente constituye el mundo tal como nos es dado; el mundo tal como nos lo da la ciencia es un mundo ligeramente diferente de nuestro mundo, un mundo constituído con ayuda de instrumentos que añadimos, por decirlo así, a nuestros sentidos. Observemos, en fin, que lo que alcanzamos con ayuda de estos instrumentos y estos cálculos, es lo que podríamos llamar la infraestructura de lo real mucho mejor que su estructura. Y lo 
propio de la actividad científica, que es una de las más altas actividades del espíritu, que constituye una de las más esenciales superestructuras de éste, es hacernos alcanzar lo que en lo real es infraestructura.

Habiendo examinado diversas teorías filosóficas, racionalismo y empirismo, luego la teoría de la realidad y la de la totalidad, luego aún el recurrir a ciertas experiencias $y$, por último, el recurrir a la ciencia, podríamos preguntarnos si no habrá que poner en primer término cierta parte de la filosofía que se desarrolló particularmente en el siglo xIx y es la teoría del conocimiento, la epistemología. Pero lo que decíamos hace un momento acerca de la ciencia, a saber, que tiene su punto de partida en lo que podemos llamar, al menos provisionalmente, el sentido común, nos inclina a decir asimismo que aquello ante lo que estamos es lo real y no nuestro conocimiento de lo real; que para llegar a una teoría del conocimiento, para consideramos a nosotros mismos en cuanto cognoscentes, hay que ver las cosas de soslayo, por decirlo así, mientras que natural y directamente vemos el mundo. Además podemos observar que toda teoría del conocimiento implica una teoría de la realidad tanto como la teoría de la realidad implica una teoría del conocimiento; y como acabamos de decir que la teoría de la realidad es más directa, sin duda es por ella por la que naturalmente conviene comenzar.

¿Quiere decirse que no hay nada que retener de las grandes teorías clásicas? ¡Lejos de ello! Pongamos por ejemplo algunas verdades que nos parecen adquiridas, la primera sentada por Platón y Aristóteles, la segunda por Kant, la tercera por Heráclito y Bergson, la cuarta por Platón y Hegel. La primera consiste en la afirmación de que no hay verdad ni error más que en el juicio; esta teoría clásica, puesta en tela de juicio por Heidegger, nos parece debe subsistir si se da a la palabra verdad su sentido propio. La segunda es que la existencia es posición. La tercera, que no hay nada estable en la naturaleza y que todo está en movimiento. La cuarta, que no hay unidad más que de una multiplicidad, que la unidad abstracta no es más que una pura ficción.

Se ha hablado de un retorno a lo concreto; para nosotros, todo acto de mediación se explica por algo inmediato que le es anterior. Al afirmar que lo inmediato es lo concreto, queremos decir que lo que nos es dado primitivamente, es un conjunto. A decir verdad, no hay palabra que pueda ser aquí satisfactoria, pues que ideas como la de síntesis, e incluso la de conjunto, suponen elementos primitivamente separados que luego serían reunidos, mientras que, para nosotros, lo que hay antes que nada es una totalidad no descompuesta que ni siquiera podemos llamar legítimamente totalidad. Toda síntesis es re-síntesis, y re-hechura de esta "totalidad" inicialmente dada.

Sin duda los racionalistas, vincúlense a las ideas de Hegel o incluso a las de Kant y los que prosiguen su obra, dirán que lo que llamamos concreto es en verdad lo abstracto, que el empirismo siempre acaba por fundarse en una 
abstracción de una u otra suerte. Aquí el diálogo es muy difícil de proseguir; y esta misma dificultad de la prosecución del diálogo será a su vez interpretada diversamente por los racionalistas, que verán en ella el reconocimiento de que el diálogo no puede proseguirse más que en un clima racional, y por nosotros, que veremos en ella el hecho de que todo diálogo presupone algo anterior al diálogo.

La fenomenología nos aporta elementos preciosos, aunque no fuese más que su respeto por lo que hace su aparición en la experiencia, su voluntad de describir. Sin duda, no puede darnos más que algo previo y como un punto de partida. Al menos podemos cobrar conciencia de este punto de partida. Acabamos de pronunciar las palabras: cobrar conciencia; digamos que no podemos cobrar conciencia más que de algo que previamente, previamente a lo previo de que acabamos de hablar, era inconsciente. La fenomenología nos hacía percatarnos, antes de todos nuestros juicios, e incluso antes de todas nuestras percepciones, del dominio pre-predicativo, e incluso del dominio de lo pre-dado. Dicho de otra manera, todas las relaciones en que descomponemos la experiencia implican un elemento sub-relacional. Llamemos aún este dominio el de la cualidad, a pesar de la aparente paradoja que hay en llamar cualidad algo de lo que decimos que es anterior al juicio, y llamémoslo aún el dominio de la facticidad.

Es también el dominio del sentido común, el que probó a describir Berkeley al mostrarnos la realidad de las cualidades segundas, más primaria que las cualidades primeras.

Hablábamos del sentido común, pero hay que ir más lejos que él y por debajo de él. Y entonces dejaremos de encontrarnos ante esa sucesión de presentes instantáneos, ante esa materia inerte, ante ese mundo infinitamente somero que nos presenta la ciencia. Estaremos en medio de un mundo compacto, de una naturaleza vibrante. La filosofía moderna ha hecho del mundo ordinario una apariencia; digamos que la pintura moderna ha hecho de la apariencia una realidad extraordinaria. El pintor moderno nos coloca ante un espesor de espacio y de duración, duración de las cosas y duración de él mismo. Es un rasgo común a varias filosofías contemporáneas la rehabilitación de la idea de apariencia; podemos evocar a este propósito los nombres de filósofos tan diferentes como Nietzsche, James y Husserl. El primero reanuda la tradición de los sofistas, interrumpida por toda la cadena de los grandes filósofos clásicos, y celebra la bella apariencia; el segundo nos enseña a ver las cosas tales como se nos presentan en nuestro conocimiento, as they are known us; el tercero nos invita a estudiar la esencia en las apariencias mismas. Así, al mismo tiempo que asistiremos a un estallido de la idea de ser, seremos testigos de un ahondamiento de la idea de apariencia.

La meditación sobre la obra nos permitirá también percatarnos de la manera de que podremos superar la alternativa entre la subjetividad y la ob- 
jetividad, entre lo interior y lo exterior. Un cuadro que admiramos no está ahí, delante de nosotros, como un objeto exterior; no estamos solamente delante del cuadro; estamos más allá de la alternativa entre el "delante" y el "dentro". La comunicación entre él y nosotros es cosa distinta de una simple presencia del uno al otro, a menos que no ahondásemos también la idea de presencia.

Con menos rodeos que Bradley, con tan pocos rodeos como Parménides, el pintor y el que ve la pintura captan algo que es real, y este algo es ese conjunto de realidades que de ordinario aplana el filósofo y que ahora se nos presenta en todo su carácter pasmoso y difícil.

Decíamos que el empirismo clásico nos presenta cosas planas, exteriores unas a otras y exteriores a nosotros mismos. De este empirismo puede dar fácilmente cuenta el racionalismo; pero hay un empirismo más alto, del que tuvieron el presentimiento James y Bergson y que no le cede al racionalismo en dificultades. Vendría a juntarse con aquel empirismo trascendental de que tuvo Schelling la idea.

Estudiando a partir de aquí las ideas que han dominado la metafísica clásica, y en particular las ideas de sustancia, esencia, forma y ser, descubrimos que nada queda de ellas bajo un punto de vista puramente intelectual, que se fundan en disociaciones ilegítimas, estabilizaciones, objetivaciones que no pueden justificarse completamente. En este punto no hacen Bergson y Whitehead más que continuar la obra emprendida por Berkeley y proseguida parcialmente por Biran. Y, sin embargo, queda algo de esas ideas, una significación, pero que no debe diriginnos hacia términos intelectuales separados; si, por comodidad, tomamos primero la idea de forma, podremos ver que es de una manera indebida como se separan materia y forma, y que esta misma separación condujo a ligar la idea de forma a la de actividad del espíritu, mientras que, en realidad, teorías tan diferentes como el materialismo dialéctico, la filosofía de Whitehead, la teoría de la forma propiamente dicha, nos llevan a cobrar conciencia de una forma que no es forma, sino que está formada y presente en el seno de las cosas y que, finalmente, no se distingue de ellas. A partir de aquí podremos servirnos de las ideas de sustancia y esencia de una manera complementaria, por decirlo así, designando por sustancia la opacidad no intelectual que hay en el fondo de las cosas, por esencia una especie de trasparencia, pero no intelectual, igualmente, y más bien afectiva, aquella de que nos ha dado idea un Marcel Proust en su platonismo no platónico. La forma formada, la sustancia opaca, la esencia afectiva - gracias a estas tres realidades, unidas profundamente una con otra, somos en el solo sentido en que hoy puede tomar la filosofía la palabra ser, es decir, como ser en el mundo.

Quedaremos así preparados para proseguir la revista de las grandes ideas filosóficas con el estudio de las que en el esquema clásico completan las pri- 
meras. Las mismas separaciones que opera la filosofía clásica hacen que para ella si hay forma, sea porque hay materia, si hay sustancia, sea porque hay accidente. Si existen los términos sustanciales y esenciales, es menester que haya también relaciones. $\mathrm{Y}$ no hay solamente afirmaciones; también hay negaciones. ¿Qué pasa, pues, con esas ideas que son la materia, el accidente, la relación y la negación? Acerca de la relación podemos hacer dos observaciones: una, que el origen de la relación será afectivo, lo mismo que el origen de los términos - y James y Whitehead han insistido sobre lo que llaman las relaciones sentidas-; la otra, que jamás deben separarse completamente las relaciones de los términos, ni tampoco los términos de las relaciones, siendo, por lo demás, posible incluso que haya que superar este esquema, términos-relaciones, y, conforme a las indicaciones de Bradley, ver en él una ficción, por lo demás útil, de nuestro espíritu.

Las ideas de relación y negación están ligadas unas a otras, siendo la negación una suerte de relación; como lo había advertido Platón, un término se define y es por el hecho mismo de no ser tal otro. Con frecuencia, los filósofos contemporáneos han ido de la idea de negación a la afirmación de la nada, han explicado la negación por la nada; pero si es cierto, como creemos nosotros, que la idea de la nada es el producto de una abstracción, y de una abstracción de segunda potencia, por decirlo así, no hay que remontar de la idea de negación a la idea de la nada, sino más bien trazar el origen de la negación a partir de las experiencias negativas primitivas, experiencias de repulsa, de reconcomio, de remordimiento; y aún aquí nos hace la reflexión encontrar de nuevo la afectividad originaria.

La idea de materia se nos presentará como significándonos lo que hay de irreductible en la presencia de las cosas; $y$, en este sentido, fácilmente puede irse de esta idea a la de accidente, a la idea de la irreductibilidad del hecho, a lo que los filósofos contemporáneos entienden con frecuencia por la palabra facticidad.

Facticidad, negatividad, afectividad, devenir, con estos cuatro vocablos podremos caracterizar la experiencia tal como entonces se nos presentará. Podemos, por lo demás, advertir que la afirmación de la relatividad no significa que no debamos llegar a un dominio que podemos Hamar el dominio subrelacional. Así, relaciones sentidas, una materia opaca, dos elementos de facticidad y negatividad, y por lo mismo de relatividad y devenir, he aquí lo que completa la sustancia opaca, las esencias afectivas, las formas formadas y el ser en el mundo. De las ideas clásicas de sustancia, esencia, forma y ser, y de lo que al pronto parecía oponerse a ellas, hemos vuelto cada vez a un mismo fondo de realidad, y cada vez hemos descubierto de nuevo el dominio de la cualidad, de lo sentido, de lo pre-predicativo, de lo sub-relacional.

Pero debemos tener en cuenta el hecho de que la ciencia moderna se ha esforzado por hacer entrar los accidentes, las relaciones, la materia (todo 
lo que parecía no entrar fácilmente en la sustancia, la esencia y la forma) en esquemas racionales. En Descartes se reduce la materia a la extensión. La extensión y el tiempo, la causalidad, la medida, permiten al espíritu dominar de cierta manera este mundo opaco y sentido que nos esforzamos por señalar. Pero si fijamos la atención en el origen, por una parte, del espacio y el tiempo, de la causalidad y la medida, $y$, por otra parte, en la manera de que hoy en día se presentan a nosotros esas ideas, nos daremos cuenta de que también ellas, en todo como las ideas precedentes, tienen un origen cualitativo en el espacio originario, en el tiempo originario, en lo que se ha llamado la eficacia causal, en la medida cualitativa; y veremos igualmente, si tomamos la ciencia actual, que estamos en presencia de un espacio que ya no es el espacio de la filosofía clásica, de un tiempo para el que ha acabado por no tener sentido la instantaneidad, y de una relación que ya no puede clasificarse dentro del cuadro clásico del determinismo.

Lo que hemos dicho de las ideas clásicas y de su destino actual, el lugar que hemos dado a las ideas de relación y negación, muestra que ya no puede haber oposición absoluta entre el ser y el devenir. Filósofos tan diferentes como Bertrand Russell y Nicolai Hartmann han dicho que la historia misma de las doctrinas nos muestra una especie de triunfo de Heráclito sobre Parménides. La ley del mundo real, nos dice Hartmann, es el devenir. Notemos a este propósito que el pensamiento de Platón, después del Fedón, parece haberse hecho más flexible, y que lejos de oponer un mundo del reposo, que sería el mundo verdadero, y el mundo del devenir, Platón hace observar, por una parte, en el Sofista, que hay que admitir entre las ideas el movimiento, la vida y el alma, y, por otra parte, en el Filebo, que hay lo que llama una generación hacia el ser, que hay esencias devenidas. Así, lejos de que haya que separar dos mundos, conviene ver movimiento en el seno de las ideas y estabilidades, al menos relativas, en el mundo de las cosas, en el mundo sensible.

Lo que acabamos de decir del devenir permite comprender que en medio de él encontremos núcleos de estabilidad y que en él descubramos ritmos. El devenir no deja de ser una idea abstracta más que porque vemos sus heterogeneidades y sus ritmos o sus diferentes niveles. Lo mismo diríamos de la cualidad; no hay una cualidad en general, hay cualidades. Nuestro mundo se asentará, será asentado como una jerarquía de devenires y cualidades. Veremos así jerarquizarse de una cierta manera las cosas en nuestro mundo, que sin embargo no se presenta como obediente a un orden que estuviese dado desde toda la eternidad.

Acabamos de hablar de nuestro mundo; y, en efecto, es uno de los caracteres de la filosofía contemporánea haber devuelto un lugar a la idea de mundo, esa idea que en el fondo desaparecía de la especulación de un Descartes, esa idea que ya no se presentaba más que como una idea en el hori- 
zonte de la especulación de Kant. Es mérito de Husserl y Heidegger haber vuelto a introducir esta idea, bajo la forma de la Lebenswelt, por una parte, del ser en el mundo, por otra.

¿Qué es esta Lebenswelt, qué es este ser en el mundo? Está hecho de útiles, y de una manera más general, de cosas que se presentan como instrumentos y útiles, por una parte, $y$, por otra, de cosas que se presentan como espectáculo. Pero ¿qué es esta idea misma de cosa? Y, aquí aún, vemos reaparecer en la especulación contemporánea la idea de cosa, como habíamos visto reaparecer en ella la idea de mundo. Así los empiristas como los racionalistas parecen haber disociado la idea de cosa, sea en conjuntos de sensaciones, sea en conjuntos de sensaciones y formas. Así hicieron evaporarse la idea de cosa. Pero ella reaparece, tanto, por lo demás, en un poeta como Rilke, cuanto en un filósofo como Husserl. Siempre será una cuestión la de saber si puede haber, independientemente del hombre y propiamente hablando, cosas; si no es el pensamiento del hombre lo que no solamente, y sobre todo, recorta las cosas, sino que las dota en su centro, por decirlo así, de algo análogo a lo que el hombre se figura dentro de sí como un alma. La cosa es un centro de actividad; podríamos decir, al menos míticamente, que la cosa es una persona muda, como las personas son cosas parlantes y pensantes.

Si partimos así de las cosas, nos será natural adoptar una hipótesis de Herbert Spencer, según el cual las cosas crean los órganos de los sentidos más aún de lo que los órganos de los sentidos crean las cosas.

Para Descartes, la materia se reducía a la extensión. Para nosotros, como para Berkeley, la idea de extensión es una idea abstracta; y lo que hay primitivamente son esas partes de extensión de las que ni siquiera podemos empezar diciendo que son partes de extensión, y que son las cosas. Entre estas cosas y las personas, habrá los cuerpos; y aquí aún, como en la idea de mundo y en la idea de cosa, encontramos que la especulación contemporánea da a esta idea un lugar que no había tenido antes. Sin duda se encontrarían, así antes de Descartes como en Descartes, antecedentes de esta especulación contemporánea; recordemos lo que dice Descartes de la unión del alma y el cuerpo, la manera de que los junta Biran, a la vez en su Diario, donde muestra la influencia profunda del cuerpo sobre el alma, y en su filosofía, por el lugar que da a la idea de esfuerzo. Pero quizá sea sobre todo en Gabriel Marcel, por una parte, y en Merleau-Ponty, por otra, donde veríamos, no explicada, sino más bien expuesta esta unión profunda de las dos sustancias, que justo con ello dejan, por lo demás, de ser sustancias.

A decir verdad, precisamente porque ya no puede distinguirse el alma del cuerpo, no habrá, hablando propiamente, teoría del alma en esta filosofía contemporánea tal como nos la representamos. No hay una substancia que se definiría por ella misma y que sería independiente así del cuerpo como de las cosas. Digamos que la idea de alma está reemplazada por la idea de existen- 
cia, precisamente en tanto que ésta no implica de suyo un alma separada del cuerpo, y en tanto que la existencia está, como dice Heidegger, naturalmente fuera de sí:

No es asombroso que no pueda definirse la existencia; o que si puede definirse, no pueda hacerse más que por conjunciones de antítesis; la existencia es a la vez fusión con el objeto y distancia por respecto al objeto; es a la vez grieta, rotura esencial, y perfección, o, como dice Whitehead, entelequia.

Igualmente, aún, habrá en la existencia unión de la subjetividad y la objetividad. Una vez aún podemos partir, para definirla, de la actividad de los poetas y los pintores. La interrogación de un Van Gogh hace vacilar su sol. Van Gogh cava profundidades harto más profundas, harto más cavadas que la del canto clásico. Lo mismo un Baudelaire. Es esta intensidad, producto de una desgarradura sentida entre el sujeto que se abisma y el objeto que él exalta, lo que constituye la verdad del alma moderna. Pero al mismo tiempo nace una nueva objetividad. Cézanne querría ser el pintor de una naturaleza verdaderamente naturaleza, sin pintor, donde las formas se equilibran y sitúan por sí mismas. Van Gogh se absorbe en tal amarillo. Es la verdad-objeto, después de la verdad-sujeto, como Heidegger y Jaspers identifican la verdad con el ser, mientras que Kierkegaard, su maestro a pesar suyo y a pesar, por lo menos, de uno de ellos, la había identificado con el sujeto.

Mientras que hay una psicología racional, no puede haber teoría racional de la existencia, ni siquiera puede haber teoría de la existencia; hemos visto la existencia como constituyéndose esencialmente a partir de sentimientos; el sentimiento no vive intensamente más que cuando está escondido; y no puede haber explicitación completa de ese sentimiento de conjunto que es sentimiento de la existencia.

Así como hemos dicho que las personas no están separadas de los cuerpos ni del mundo, asimismo diremos que no están separadas unas de otras; comunican naturalmente unas con otras; y he aquí aún un carácter de la filosofía contemporánea que tenemos que añadir al precedente: lo mismo que las ideas de mundo, cosa, existencia, está la idea de comunicación puesta en el centro de la reflexión de los filósofos contemporáneos. Digamos que es partiendo de Hegel y de esa lucha entre el amo y el esclavo esencial, según él, para el reconocimiento del primero por el segundo, como se ha desarrollado este problema de la comunicación. Pero digamos también que no encontró su forma contemporánea decisiva más que partiendo del gran adversario de Hegel, partiendo de Kierkegaard. De la meditación de su soledad por Kierkegaard $y$, podríamos decir, de su sentido previo de la imposibilidad de la comunicación, han nacido todas estas teorías recientes de la comuni- cación. No olvidemos, por otra parte, que en la psicología genética se abría paso la idea de que el individuo no es anterior a la comunidad de los individuos; Baldwin, Royce, Hocking habían insistido en esta contemporanei- 
dad de lo social y lo individual. En la escuela fenomenológica, se colocaban Husserl y Scheler ante la comunicación como ante un problema, problema que resolvía el segundo con ayuda de la idea de simpatía. Puesto que la comunicación es un fenómeno afectivo, antes de ser un fenómeno intelectual, es natural que se conciba el problema no como pudiendo resolverse con juicios predicativos, sino más bien como suprimido por la idea de ruego, de invccación, como en Buber, G. Marcel, Berdiaeff.

Habíamos dicho que no puede abordarse la teoría del conocimiento más que una vez constituída la teoría de la realidad; y la misma cosa diríamos de la teoría del lenguaje, de la teoría del valor. El fundamento natural de la teoría del conocimiento es la percepción; y lo que hemos dicho de nuestro ligamen con el mundo nos hace comprender que la percepción es nuestro punto de partida natural. Husserl ha hecho observar con razón que la percepción no puede explicarse, a título de nada, como un caso particular de la alucinación; es, antes bien, la alucinación la que debe explicarse partiendo de la percepción. De una manera general, dos rasgos complementarios, a primera vista contradictorios, pueden tenerse por característicos de las teorías del conocimiento contemporáneas. El primero se ve particularmente en la fenomenología: es la insistencia en lo que hay de específico en el conocimiento. Tal es el fenómeno que se mienta en la fenomenología bajo el nombre de intencionalidad. El segundo se ve en las teorías de Alexander, de Whitehead, en tanto que éstos consideran el conocimiento como un caso particular de un fenómeno más general, que llama Alexander la copresencia y Whitehead la prehensión. La ventaja de la idea de copresencia es que insiste en el aspecto de pasividad del conocimiento; lo que no nos impedirá decir que la ventaja de la idea de prehensión es insistir en el aspecto de actividad. Es que, en el fondo, estas dos ideas de actividad y pasividad no pueden ni una, ni otra, tomadas separadamente, ni siquiera tomadas juntas, caracterizar el conocimiento.

A partir del problema de la exterioridad de las relaciones, tal como se ha planteado en la filosofía inglesa y americana contemporáneas, podemos darnos cuenta de ese misterio fundamental que reside en el centro de la teoría del conocimiento. Por una parte, como han dicho los realistas, no hay verdaderamente conocimiento más que si éste deja ser tal cual es el objeto; por consiguiente, si hay una exterioridad de los términos por respecto a su relación; y, por otra parte, es forzoso sentar igualmente que no hay jamás una exterioridad completa, que el esquema término-relación es inadecuado a lo real. Es, por lo demás, lo que puede explicarnos que haya lo que puede llamarse una dialéctica del realismo, que va de una teoría de la trascendencia de los términos por respecto a las relaciones a una teoría de la inmanencia de los términos a sus relaciones.

Sabida es la importancia de la teoría del lenguaje en la filosofía contemporánea. Por lo demás, puede haber del lenguaje teorías del todo dife- 
rentes, unas que se atienen al lenguaje formulado, e incluso formalizado, puesto en forma lógica; tal el positivismo lógico; otras que se interesan por el hombre en cuanto parlante: tal será la fenomenología del lenguaje como la concibe Merleau-Ponty. Lenguaje y pensamiento no pueden separarse uno de otro. Podemos recordar el sentido de la palabra logos, que significa a la vez lenguaje $y$ pensamiento indisolublemente unidos.

Empezamos por hacer constar la existencia en su naturaleza misma; después la vimos en su relación, por una parte, con lo que ella conoce, por otra parte, con lo que ella expresa; es decir, que la hemos estudiado en tanto que es logos como conocimiento, por una parte, y en tanto que es logos como expresión, por otra parte. Ahora debemos ponerla igualmente en relación con lo que ella pone de cierta manera por encima de sí, es decir, con el valor. Lo mismo que en la teoría del conocimiento estábamos frente a una especie de dificultad que venía de que por sí mismo pone el conocimiento los términos a la vez como independientes de él y dependientes por respecto a él, aquí estaremos frente a la dificultad que viene de que nos hace falta ver el valor a la vez como una posición efectuada por la existencia y como independiente de la existencia y superior a ella. Hay que añadir incluso que tiene sus raíces en la existencia. Quizá sea esta afirmación, de que el valor tiene sus raíces en la existencia, lo que nos permita comprender a la vez que dependa de la existencia y que se lo considere, por la existencia misma, como superior. He aquí el triple carácter que descubriríamos en las teorías contemporáneas del valor, según que insistan más sobre la inmanencia del valor a la existencia, sobre su libre posición o sobre su trascendencia. Pero solamente si tenemos esta triple idea, o más exactamente, este triple sentimiento, comprenderemos el valor en toda su esencia. A decir verdad, cuando se trata del valor, lo mismo que cuando se trata de la existencia, lo que importa es menos comprender intelectualmente que efectuar la operación que les corresponde, es decir, vivirlos. Y vivimos el valor cuando tenemos el sentimiento de poder sacrificar algo a esta "realidad" que colocamos por encima de nosotros; el valor se forma, por decirlo así, y como lo indica la palabra misma de sacrificio, con el sacrificio. Debemos darnos también cuenta de que no puede haber solución general del problema del valor, ni podemos llegar a vivir el valor más que partiendo de los problemas particulares que se nos plantean.

Pero, al fin y al cabo, debe retenerse esta palabra misma de valor, empleada tan frecuentemente en la filosofía contemporánea. Advirtamos que las teorías del valor se forman particularmente en el momento en que disminuye el sentido del valor. En una teoría como la de Platón es bien difícil distinguir una parte que sería teoría del valor y una parte que sería teoría de la realidad.

Hemos definido la existencia en sus relaciones con el conocimiento, el lenguaje y el valor. De esta triple manera la definimos por respecto a lo que 
le es exterior, preséntese este exterior como la intencionalidad en la que la existencia apunta a un objeto, en la palabra con que se expresa o en el principio que pone por encima de sí. De estas tres maneras hemos implicado en la existencia la idea de una trascendencia; y en la tercera manera de implicar la trascendencia, hemos visto la existencia como poder de definirse y sentirse por respecto a lo que le es superior. Es lo que nos permitirá desprender el sentido último de la trascendencia en tanto ésta es la afirmación de algo distinto y Absoluto, de un término irreductible y superior a la existencia. Pero aquí más aún que en los casos precedentes nos encontramos en presencia de antinomías que vienen de que hay - para recoger una expresión de Kierkegaard - como una lucha a muerte entre la existencia y la trascendencia, al mismo tiempo que ambas viven por obra de esta misma lucha. La existencia tiende a matar la trascendencia, como lo vio Nietzsche; la trascendencia tiende a matar la existencia, como dirían ciertos espíritus formados en la escuela de Kierkegaard. Y no podremos llegar finalmente más que a una suerte de ontología negativa; ¿puede nombrarse la verdadera trascendencia? ¿Puede ni siquiera pensarse? Estamos aquí en presencia de un doble peligro: peligro que consistiría, sea por una parte en poner una inmanencia que se bastase a sí misma, sea por otra parte en poner una trascendencia objetivada. Se trata de colocar por encima de nosotros realidades que acogemos como superiores y a las que nos sometemos, sin que no obstante podamos afirmar que no son creaciones de nosotros mismos. La trascendencia debe más bien quedar en estado de cuestión que no presentársenos como solución; y el eco de esta cuestión debe vibrar en nuestro interior y volver nuestra alma vibrante, sin que jamás podamos esperar llegar a resolver las antinomías ante las que nos coloca.

Pero dno podemos preguntarnos si esta idea no acabará por suprimirse, por arrebatarse a sí misma? ¿No podemos rebasar de alguna suerte el rebasar, efectuar una operación que podríamos llamar la trascendencia de la trascendencia? Pero aquí estamos en presencia de un nuevo peligro. Si trascendemos la trascendencia ¿no recaemos en lo inmanente? Si no hay más que el mundo o la realidad, ¿no corremos el riesgo de ver desvanecerse lo que puede dar un valor precisamente a lo real y al mundo? ¿No corremos el riesgo de ver desvanecerse el valor y la trascendencia? Aquí es donde podrían servirnos las dos ideas de naturaleza y destino, la una poniéndonos en presencia de esa fuerza de crecimiento que hay en el fondo de las cosas y que no puede llamarse ni inmanencia, ni trascendencia, la otra poniéndonos en presencia de esa unidad que podemos hacer de nuestra vida, trasformando, según ciertas ideas de Nietzsche, lo que se nos impone como fatum en una totalidad querida por nosotros.

¿Hay un destino de la filosofía? Si ponemos la vista en la serie de los sistemas filosóficos, comprobamos a menudo que a un sistema viene a opo- 
nerse el sistema que le es más contrario; así es como a Heráclito sucede Parménides; o para tomar el otro extremo de la historia de la filosofía, así es como, en el siglo xrx, al idealismo monista vienen a oponerse realismos pluralistas. Esta dialéctica de los sistemas no debe hacernos perder de vista, sin embargo, que entre los opuestos son posibles, y a veces reales, toda suerte de gradaciones, toda suerte de mediación. Aun teniendo en cuenta estas mediaciones, podemos explicar el devenir de los sistemas por el hecho de haber una realidad frente a la cual se encuentran los filósofos al mismo tiempo que se encuentran en medio de ella y que no sufre se la exprese en un solo sistema. Así, el espíritu humano va de uno a otro, no por una dialéctica que le sea puramente inmanente como en Hegel, sino por una dialéctica que se explica por la exterioridad misma de lo real. Pero esta palabra de exterioridad puede suscitar, a su vez, una cuestión: como decíamos, el espíritu está en lo real al mismo tiempo que frente a ello; y esta exterioridad no es, pues, una exterioridad absoluta.

Tenemos que interrogarnos, en segundo lugar, sobre la posibilidad de una dialéctica en el interior mismo de los sistemas. Observaríamos que a veces vienen a coincidir las formas más opuestas de las doctrinas; un realismo extremo puede coincidir con un extremo idealismo. Meeting of extremes sobre el que llamó Bosanquet nuestra atención.

De esta doble manera estamos en presencia de una dialéctica, pero de una dialéctica sin síntesis, de una dialéctica hecha de tesis y antítesis, que es, por lo mismo, una dialéctica de la intensidad.

Nuestra posición en el mundo es tal, que sin duda no podemos describir éste, ni podemos describir nuestra misma posición más que uniendo una antítesis a otra. El conocimiento es a la vez distancia y fusión. Por doquier encontraremos tales uniones de antítesis. La evolución misma de la ciencia nos ha hecho ver cómo ésta va de una visión continua del universo a una visión de lo discontinuo. El juego de los sistemas nos presenta una unión de lo mediato y lo inmediato. Para el filósofo se trata, como lo había visto Platón y como lo ha visto Whitehead, de unir el ser y el devenir. El tiempo y el espacio son a la vez fusión y distinción. Y el problema, planteado sobre todo en la filosofía inglesa, acerca de las conexiones entre las relaciones y los términos, no puede resolverse más que con la doble afirmación de la independencia de los términos por respecto a sus relaciones, por un lado, y de su dependencia, por otro.

Diciendo que la dialéctica concebida por nosotros no es inmanente, implicamos que hay fuera de la dialéctica lo que puede representarse como su punto de partida y lo que puede representarse como su punto de llegada. La dialéctica se sitúa, entonces, entre dos momentos no dialécticos, entre dos 
silencios de la dialéctica. Habíamos dicho que trascendemos la trascendencia; y ahora vemos que trascendemos la dialéctica. Con el primer movimiento, volvemos al mundo tal cual nos es dado; con el segundo, lo concebimos como el punto de partida y el punto de llegada del movimiento dialéctico.

Con gusto diríamos que hay palabras que son dialécticas por sí mismas; tal es el caso de la palabra trascendencia, de la palabra absoluto, pues que la primera designa a la vez el movimiento del espíritu y el término hacia el cual se hace el movimiento, y pues que la segunda ha venido desde su primera significación (lo separado) hasta una significación en apariencia contraria del todo (lo que todo lo engloba).

Si nos interrogásemos sobre las relaciones entre las ideas que hemos expuesto y las del materialismo dialéctico, podríamos decir que con este materialismo tenemos en común la afirmación de la independencia de lo real respecto del pensamiento y el no sernos tampoco extraño el elemento dialéctico que está incluso en tal materialismo. Pero quizá éste, si se lo lleva bastante lejos, haría estallar los cuadros mismos del materialismo, pues que su idea de materia ya no tiene nada de común con lo que en otro tiempo se entendía por esta palabra.

La filosofía no es una totalidad que se baste a sí misma. Se nutre de lo que no es ella. Se nutre de la no-filosofía. Las ideas no existen más que por obra de lo que no es idea. Lo que es anterior y lo que es posterior a la filosofía le es, pues, necesario. Así volvemos sin cesar a nuestro punto de partida; pero enriquecidos por los pasos que hemos dado.

Echando una ojeda a las filosofías recientes, comprobamos que algunos de los más grandes filósofos contemporáneos se han vuelto a menudo contra las filosofías anteriores. Kierkegaard, Jaspers, Whitehead, Heidegger han criticado severamente, a veces injustamente, a Descartes. Nietzsche, Kierkegaard, James, Bergson, Heidegger han criticado a Platón. Kierkegaard, James, Jaspers han atacado a Hegel. Hay, pues, como una rebelión del pensamiento contemporáneo más activo contra los grandes filósofos del pasado. Pero al mismo tiempo se ahonda la visión que tenemos de estos grandes filósofos. Diríamos que cada uno es trascendente respecto de sí mismo; así es como hemos tenido ocasión de señalar el lugar de la idea de devenir en Platón; así es como se ha renovado nuestra visión de Descartes y de lo que hay en él de irreductible al cartesianismo corriente. Y podríamos hacer la misma observación acerca de Kant.

Ciertas cuestiones se han precisado; otras han desaparecido; y se presentan nuevos problemas. Pero, de una manera general, podríamos decir que pensar es volver hacia el origen del pensamiento, es pasar por la inteligencia para sobrepasarla, es intentar coger a un inconsciente que no puede cogerse completamente. Recordemos las palabras de Heráclito cuando decía que hay que esperar aquello de que no cabe esperanza, que hay que encontrar el tesoro 
imposible de encontrar, hacia el que no hay camino. No creamos que, como se ha dicho, el ser se esconda; ni tampoco creamos que se revela; es todavía Heráclito aquel a quien recurrimos, cuando nos dice: "El príncipe no se esconde, ni se revela, sino que significa." El príncipe, el Principio, es el Otro absoluto, por el que somos, lo mismo que él es por nosotros.

JEAN WAHL

(trad. José Gaos) 